\title{
Study of Intra Ocular Pressure Changes after Isometric Handgrip Exercise Test in Young Adults
}

\author{
Priya CRao', Nataraj S.M ${ }^{2}$ \\ ${ }^{1}$ Associate Professor, Subbaiah Institute of Medical Sciences, Purale, Shimoga, \\ ${ }^{2}$ Professor \& HOD, Department of Physiology, JSS Medical College, Mysore
}

\begin{abstract}
Objective: ToStudy the effect of isometric handgrip exercise test on Intra ocular pressure in young adults

Method: Healthy young male adults in the age group of 18-22 years were selected among MBBS phase I students of a Medical college .Sample size was 40 . Heart rate and IOP were recorded at rest and after isometric handgriptest

Results: Right eye IOP has decreased significantly from resting $16.28 \pm 1.55$ to $9.30 \pm 1.79(\mathrm{p}<0.001)$ immediately after handgripexercise IOP Left eye IOP has decreased significantly from resting $16.15 \pm 1.69$ to $13.04 \pm 1.19(\mathrm{p}<0.001)$ immediately after handgrip exercise IOP
\end{abstract}

Conclusion: Isometric handgripexercise lowers IOP which were significant. Hence may prove u seful in normotensive glaucomatous patients

Key words: Intraocular pressure, Handgripdynamometer

\section{Introduction}

The Intra Ocular Pressure ${ }^{1}$ (IOP) is important in maintaining shape of the eye ball and optical integrity. IOP is known to be sensitive to many physiological variables in the body system which include age ,sex, body position, valsalvamanoeuvre, exercise, diurnal variations and pregnancy.

Exercise when performed regularly has beneficial effect on various systems of individual like physical, metabolic, and psychological. These physiological variables in body system include changes in vascular

\section{Corresponding Author:}

\section{Dr Nataraj S.M.}

Professor \& HOD Department of Physiology

JSS Medical College, Mysore

Email : natarajsm24@yahoo.in pressure, serum osmolarity, hormonal levels, decrease in blood $\mathrm{pH}$, increase in blood lactate and presence of toxins.

It is well documented that improvement of physical fitness through regular exercise can produce physiological change in the whole body especially in the cardiovascular system.

In recent years it has been documented that IOP is a dynamic function and is subjected to many influences both acutely and over long term.IOP is also known to be responsive to short- term and long- term exercise.

Glaucoma is chronic progressive optic neuropathy caused by a group of ocular conditions which lead to damage to optic nerve with loss of visual function. Most common risk factor is raised intraocular 
pressure $^{(1,4,5)}$ Relationship between isokinetic exercise \&IOP showed significant lowering of IOP after exercise $^{(2,3)}$

\section{Aims \& Objective}

ToStudy the effect of isometric handgrip exercise test on Intra ocular pressure in young adults

\section{Materials and Methods}

Healthy young male adults in the age group of 18-22 years with BMI of $18-22.9 \mathrm{~kg} / \mathrm{m}^{2}$ were selected among MBBS phase I students of a Medical college .Sample size was 40. Heart rate and IOP were recorded at rest and after isometric handgriptest.

The subjects were requested to complete a questionnaire that included inclusion and exclusion criterias. Then physical examination was carried on each participant to rule out any systemic diseases affecting IOP. The weight, height, were measured and BMI was calculated by using formula weight in $\mathrm{kgs} /$ the square of height in meter. Subjects fitting the inclusion and exclusion criterias $(n=40)$ were considered for the study. Overweight subjects (BMI$23-24.9 \mathrm{~kg} / \mathrm{m} 2$ ) and subjects with refractive errors were excluded.

\section{Inclusion Criteria}

$\mathrm{v}$ Young healthy adults in the age group of 1821 yrs of both sexes.

v Non obese BMI $18-22.9 \mathrm{~kg} / \mathrm{m} 2$.

v Normotensive $<130 / 80 \mathrm{~mm} \mathrm{Hg}$.

v Non smoker

v Non alcoholic

Subjects with Pre-existing refractive error, acute and chronic Conjunctivitis, Glaucoma, Migraine were excluded from study ${ }^{(7)}$
Materials:

- Power lab ECG.

- Schiotz tonometer

- Handgripdynamometer

AD Instrument Powerlab (Model-ML870, Serial-830-0732):

AD Instruments provides computer-based data acquisition systems for research andeducation. Powerlab data acquisition systems and choice of LabChart, LabTutor and LabAuthor software, provide outstanding data acquisition, display, analysis and authoring features for a wide range of life science applications. Since 1988, Powerlab (also MacLab) systems have been used for data acquisition and analysis by the world's best academic, government and private organizations.Powerlab systems combine software-controlled input of parameters, extensive signal conditioning options, variable sampling speeds and powerful real-time computations with the advantages of computer-based data display and analysis. They offer the functionality of a chart recorder, XYT plotter, digital voltmeter and storage oscilloscope in one compact unit. LabChart software, supplied with Powerlab systems helps in analysing the data. In the present study by using Powerlab Heart rate measurement was done on subjects in supine posture.

\section{Basic concept and theory of indentation:}

Schiotz tonometry is based on the fundamental fact that a plunger will indent a soft eye more than a hard eye. When the tonometer is placed on the cornea, immediately the different forces come into play; Wthe Weight of the tonometer, acts over an area A and indents the cornea displacing a volume $\mathrm{V}$. The tensile force $\mathrm{T}$ set up in the outer coats of the eye at every where tangentially to the corneal surface, with a component opposing $\mathrm{W}$, so that an additional force 
$\mathrm{T}$ is added to the original baseline or resting IOP (P0) which is artificially raised to a new value (. Thus the scale reading of the tonometer actually measures the artificially raised IOP

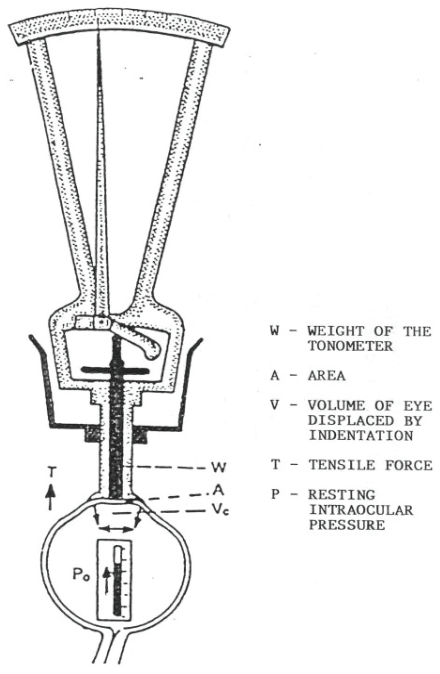

\section{Hand grip dynamometer :}

The device used to measure the grip strength is called dynamometer. It is reliable and valid in evaluation of grip strength. It is widely accepted and grip strength measurements provide an objective index of the functional integrity of the upper extremity. Measurement of grip strength by hand dynamometry is reproducible and consistent. The handgrip dynamometer is easy to handle and reliable in its measurements.

\section{Parameters}

Study was carried out in physiology department

Intraocular pressure in $\mathrm{mm} \mathrm{hg}$ in supine position using standard steps.

- Weight in kilogram. \& Height in meters were measured. BMI=Weight in $\mathrm{kg} /$ height in meter $^{2}$ was calculated to group them as normal weight.

- Heart rate

- Maximum voluntary contractions(MVC) was assessed and subjects were asked to carry out endurance isometric exercise at $40 \%$ of their MVC

\section{Study method - .}

Prospective study.

Ethical clearance was obtained from our institution Ethical committee

Prior to the procedure written and informed consent was obtained from all the subjects..

The exercise was performed in a wellventilated room. Participants were instructed not to consume beverages nor a heavy meal in previous 4hours or participate in any vigorous activities 24 hour before test

Isometric endurance contraction at $40 \%$ of the individuals MVC was executed with handgripdynamometer

In order to minimize the bias of diurnal variations of IOP and other parameters, the studies were made between $3 \mathrm{pm}$ to $4 \mathrm{pm}$.

At the reporting time subjects were asked to relax in supine position for $5 \mathrm{~min}$. Baseline IOP was recorded .Subjects executed MVC contractions of 1 second duration at 1 minute interval for 3 times .Maximum of these is considered as their MVC . Then endurance contraction at $40 \%$ of their MVC is made. Intraocular pressure and Heart rate were measured in supine position immediately (within $30 \mathrm{sec}$ ), at five, at ten, at fifteen minutes after exercise.

\section{Statistical Analysis}

Mean and Standard deviation was calculated for 
isometric hand grip exercise test in young adults. Paired t-test was applied at 5\% level to test the significance of changes in above parameters(Using Epi-Info) Microsoft Excel and EPI-INFO package were used for data entry and statistical analyses respectively.

\section{Results}

Mean and SD of IOPof right \&left eye after Isometric handgrip Exercise

\begin{tabular}{|c|c|c|c|}
\hline \multirow{2}{*}{ Parameter } & Duration & Hand Grip & P value \\
\hline \multirow{4}{*}{ Right eye IOP } & Resting & $16.28 \pm 1.55$ & $>0.05$ \\
& 1 min exercise & $9.30 \pm 1.79$ & $<0.001^{*}$ \\
& 5 min postexercise & $10.67 \pm 1.90$ & $<0.001^{*}$ \\
& 10 mipostexercise & $13.99 \pm 1.32$ & $<0.001^{*}$ \\
& 15 min pt exercise & $16.26 \pm 1.57$ & $>0.05$ \\
\hline \multirow{5}{*}{ Left eye IOP } & Resting & $16.15 \pm 1.70$ & $>0.05$ \\
& 1 min exercise & $8.91 \pm 1.74$ & $<0.001^{*}$ \\
& 5 min postexercise & $10.60 \pm 1.92$ & $<0.001^{*}$ \\
& 10 mipostexercise & $13.74 \pm 1.71$ & $<0.001^{*}$ \\
& 15 min pt exercise & $16.15 \pm 1.69$ & $>0.05$ \\
& & & \\
\end{tabular}

Data presented as mean\& SD

*Statistically significant $\mathrm{p}<0.05$

Right eye IOP has decreased significantly from resting $16.28 \pm 1.55$ to $9.30 \pm 1.79(\mathrm{p}<0.001)$ immediately after handgripexercise IOP has returned back to resting level within 15 min after exercise.

Left eye IOP has decreased significantly from resting $16.15 \pm 1.69$ to $13.04 \pm 1.19 \quad(p<0.001)$ immediately after handgrip exercise IOP has returned back to resting level within 15 min after exercise.

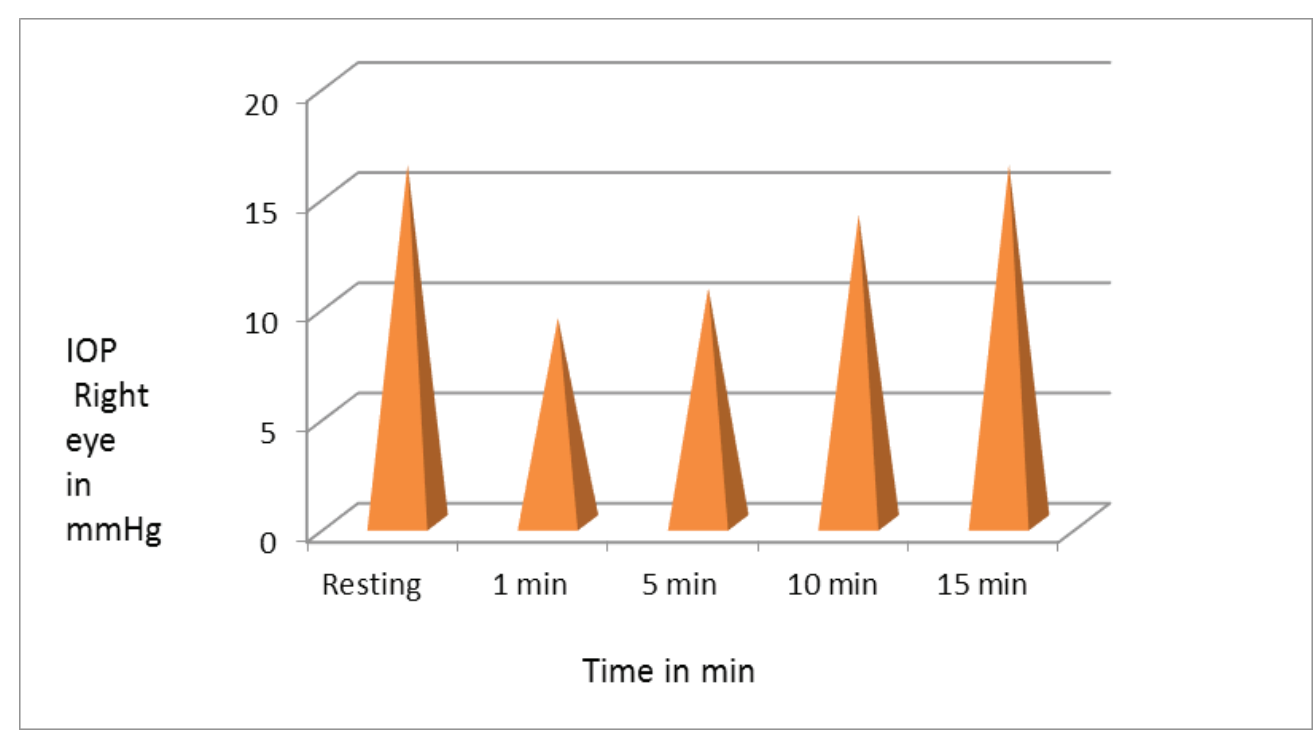




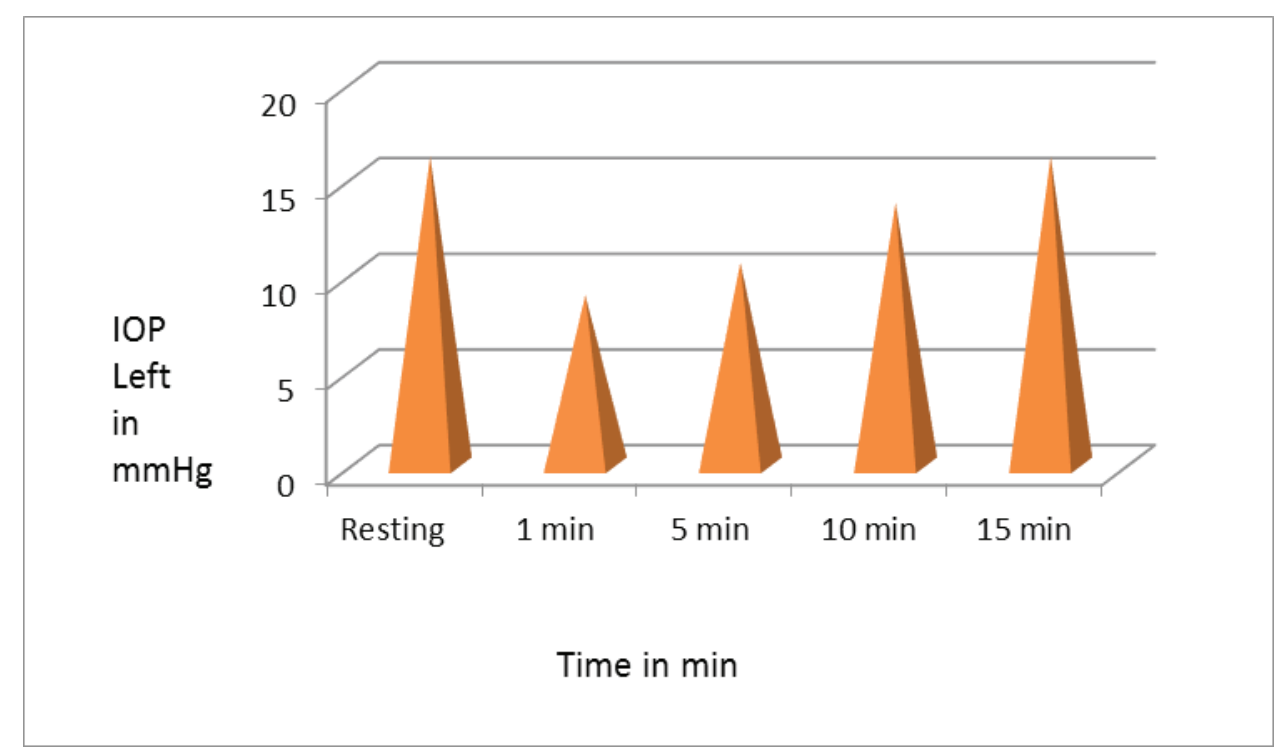

\section{Discussion}

- Isometric handgripexercise stimulate ocular sympathetic nervous system to increase the facility of outflow and thus decreases IOP . Also epinephrine stimulates synthesis of cAMP. Activation of cAMP decreases IOP by decreasing aqueous humour production $^{(6,8)}$

- Also Afterhandgripexercise there is rise in blood lactate levels. Increased Lactate levels causes outflux of water from eye which is responsible for fall in IOP (9)

- Low $\mathrm{CO}_{2}$ tension in blood is associated with a reduction of IOP after isometric (anaerobic) exercise. In his study Harris compared the drop in IOP in 2 sets of individuals. In first set subjects were made isocapnic during exercise by giving carbon dioxide and in second set subjects were not given carbon dioxide and thus stayed hypocapnic. They observed cessation in IOP drop with blockage of exercise induced hypocapnia in first set and claimed the presence of this indirect effect of exercise of reduction in IOP by inducing hypocapnia $^{(10)}$

\section{Conclusion}

Isometric handgripexercise induces raise in heart rate and simultaneously lowers IOP and both were significant. Hence may prove useful in normotensive glaucomatous patients.

\section{Conflict of Interest : None}

Source of Funding : Self

\section{References}

1. Qureshi IA. Effect of exercise on intraocular pressure in physically fit subjects. Clinical and experimental pharmacology and physiology 1996; 23(8):648-652.

2. Avundak AM, Berna Y, Imaz, Nermin S. Comparison of intraocular pressure reductions after isometric and isokinetic exercise in normal individuals. International journal of ophthalmology 1999; 213:290-294.

3. Conte M , Scarpi M J ,Rossin RA., Beteli HR, Loopes RG. Intraocular pressure variation after submaximal strength test in resistance training. Arq Bras Ophthalmol 2009 ;72(3): 351-354.

4. Dennis BA, David MA, Beck. Ophthalmic arterial hemodynamics during isometric exercise. Journal of glaucoma 1995;4:317-321.

5. Geraldo MV, Hildeamo B, Oliveira MS, Daniel 
T. Intraocular pressure variations during weight lifting. Archives of ophthalmology 2006; 124(9):1251-1254.

6. Risner et al. Effects of Exercise on Intraocular Pressure and Ocular Blood Flow: A Review. Journal of Glaucoma: Aug 2009; $18(6$ ) :429436.

7. Klein BEK, Klein R, Knudtson MD. Intraocular pressure and systemic Blood Pressure: longitudinal perspective: the Beaver Dam Eye
Study. Br J Ophthalmol. 2005; 89: 284-287.

8. Passo MS, Goldberg L, Elliot D, Van Buskirk EM. Exercise conditioning and Intraocular pressure. Am J Ophthal. 1987; 103(6):754-7

9. A K Khurana. Glaucoma. Comprehensive ophthalmology. $4^{\text {th }}$ edition. India. New age international publishers; 2007. 208-210.

10. Harris A Isocapnia bocks exercise induced reductions in ocular tension Invest Opthalmol Vis Sci 1992;33:2229-2232 